\title{
Microstructural and Wear Properties of Annealed Medium Carbon Steel Plate (EN8) Cladded with Martensitic Stainless Steel (AISI410)
}

\author{
Shubrajit Bhaumik ${ }^{1} \mathbb{D}$, Manidipto Mukherjee ${ }^{2} \mathbb{D}$, Parijat Sarkar ${ }^{1}$, Anish Nayek $^{1}$ and \\ Viorel Paleu ${ }^{3, *(D)}$ \\ 1 Tribology and Surface Interaction Research Laboratory, Department of Mechanical Engineering, \\ SRM Institute of Science and Technology, Kattankulathur, Tamil Nadu 603203, India; \\ shubrajb@srmist.edu.in (S.B.); parijats8@gmail.com (P.S.); anishnayek516@gmail.com (A.N.) \\ 2 Centre for Advanced Manufacturing and Metrology, CSIR-Central Mechanical Engineering Research \\ Institute, Durgapur 713209, West Bengal, India; m.mukherjee.ju@gmail.com \\ 3 Mechanical Engineering, Mechatronics and Robotics Department (I.M.M.R.), Mechanical Engineering \\ Faculty, "Gheorghe Asachi” Technical University of Iasi, 61-63 D. Mangeron. Boulevard, \\ 700050 Iasi, Romania \\ * Correspondence: vpaleu@mec.tuiasi.ro; Tel.: +91-40-756-797-147
}

Received: 12 June 2020; Accepted: 13 July 2020; Published: 16 July 2020

\begin{abstract}
Limited work on the wear properties of martensitic stainless-steel weld clads initiated this work which included investigations on microstructural and wear properties of cladded AISI 410 (filler wire)/EN 8 plates (substrate). Three layers of martensitic stainless steel (AISI 410) were deposited using metal inert gas (MIG) welding on medium carbon steel (EN 8) achieving a $51.5 \pm 2.35 \mathrm{HRC}$ of top layer. The elemental and phase fractions of the cladded layers indicated $98 \%$ martensite phase and retained austenite (2\%). About $40 \%$ dilution was observed between EN 8 and the first weld layer. The results of tests carried out on pin on disc tribometer revealed an enhancement of anti-wear life of the martensitic weld cladded EN 8 by three times that of uncladded EN 8 . The uncladded EN 8 plate suffered severe damage and high wear, leading to its failure at $478 \mathrm{~s}$. The failure of the uncladded EN 8 sample was identified by the occurrence of high vibration of the pin on disc tribometer which ultimately stopped the tribometer. On the other hand, the cladded EN 8 sample continued running for $3600 \mathrm{~s}$, exhibiting normal wear. After the tribo test, the surfaces of the pins of both cladded and uncladded EN 8 were analyzed using scanning electron microscope (SEM) and 3D profilometer. The surface characterization of tribo pairs indicated ploughing and galling to be the primary wear mechanisms. The average grain size of top and middle layer was in the range of $2-3.5 \mu \mathrm{m}$, while the base metal showed $5.02 \mu \mathrm{m}$ mean grain size, resulting in higher hardness of clad layers than base metal, also favoring better wear resistance of the cladded EN 8 samples as compared to uncladded EN 8 samples.
\end{abstract}

Keywords: MIG cladding; martensitic stainless steel; microstructure; wear

\section{Introduction}

Cladding is a common surface coating technique in which a thick layer of material covers a relatively low-cost structural material to enhance its mechanical properties, corrosion resistance properties, and to improve the service life [1]. The deposition is typically of superior quality, enhancing the mechanical and microstructural properties of base metal. With a refined microstructural arrangement in the top surface, the cladding material usually has the properties to withstand high temperature, impact loads, and high wear resistance. 
Due to corrosion and wear resistance of martensitic and austenitic stainless steels, they are widely used in several engineering elements of hydropower plants and gas turbine plants [2], but the hot and cold cracking of these materials makes martensitic stainless-steel fusion deposition a very difficult process [3]. The contrast between friction stir processing (FSP) and manual metal arc welding (MMAW) was emphasized on low carbon steel cladding with AISI 410, and it observed that the hardness and wear resistance in FSP was better [4] than MMAW. Several claddings, such as Al/ferritic stainless steel, stainless steel/carbon steel [5], austenitic stainless steel/Al/Cu [6], and stainless steel Ti/ferritic steel [7] are common for industrial applications. These claddings are done by weld cladding, laser cladding, thermal spraying, brace cladding, and explosive cladding. Microwave cladding is a new technique which has the advantage of low thermal distortions and low porosity [8]. It has also been reported that a hardness of $530 \mathrm{HV}$ (51 HRC) was achieved using the microwave cladding [8].

Weld cladding by metal inert gas welding (MIG) process is the most common and economical cladding process practiced in industries. Various metals such as nickel and cobalt alloys, copper alloys, alloy steels, etc. [9] are used for weld surface cladding. Gas metal arc welding GMAW (MIG) is widely accepted by industry because of certain distinct benefits $[10,11]$ but diminished spattering and no slag makes MIG to be more favorable. It has been reported that the GMAW (MIG) cladding system has high reliability, all position flexibility, and high production rate. Additionally, MIG is ferrous and non-ferrous materials friendly, clean, inexpensive, and does not use flux [12]. These factors made MIG to be easily adopted by manufacturing units. Furthermore, the shielding gas in MIG protects the deposition of the weld from damage resulting in very high-quality weld deposits.

One of the most important aspect in cladding is the weld bead penetration. A minimal weld bead penetration is always favorable as it minimizes the dilution level. Cladding involves joining of dissimilar materials, and hence cracks are formed in the fusion zone of two materials due to different thermal expansion coefficients [1]. A suitable clad bead geometry depends on the input of weld heat (current, voltage, and travel speed). It was observed that the corrosion rate for austenitic (316) stainless steel cladding on low alloy steel at moderate to low heat input was minimal [13]. In the case of a low alloy base material, the austenitic stainless-steel cladding exhibited maximum resistance to corrosion at travel speed of $145 \mathrm{~A}, 26 \mathrm{~V}$, and $535.8 \mathrm{~mm} / \mathrm{min}$ [14]. The duplex stainless-steel deposition on low carbon steel at $0.38 \mathrm{~kJ} / \mathrm{mm}$ heat input provided a desirable microstructure and a minimum corrosion rate [15]. Dhib et al. [16] reported the formation of decarburized ferrite zone and carburized austenite zone while cladding A283 with AISI 316 by hot rolling process. This was due to the transfer of elements from base material to clad, which in turn formed a diffusion layer. Cracks were mainly observed in the base material, but the bonding of base metal and cladding was sufficiently good. Also, Dhib et al. [17] reported the presence of diffusion layer between clad layer and parent metal during cladding with austenitic stainless steel on low carbon steel also. Additionally, they found that, as a result of carbon diffusion from the base metal and microstructure, grains near the straight interface were elongated perpendicular to the welding direction, which resulted in a change in near-weld interface micro-hardness [17]. The cladding of AISI $308 \mathrm{~L}$ with laser cladding process on AISI 316 showed a reduction in heat affected zone and also a good metallurgical bond, but the average hardness was found to be $236 \mathrm{HV}(41 \pm 2 \mathrm{HRC})$, while the substrate hardness was found to be 247 HV ( $43 \pm 2$ HRC) [18].

The high wear resistance properties of AISI 410 and mostly all martensitic steels recommend them as suited materials for surface coatings and hardfacing [4,19-22]. After careful grinding and flattening of the surface, it is always desirable to increase the number of deposited layers [23]. In a single-layer approach, there is a dilution from base metal [23], which decreases the hardness of the hardfaced layer and ultimately decreases wear resistance. As each layer is reheated in a multi-layer cladding system due to the deposition of the layer above it, the grains are refined in the middle layer and micro-cracks are also visible in the microstructure [24]. In several occasions, nitrogen additives were applied by replacing an amount of carbon with nitrogen by using flux-cored electrodes. This reduces the chance of retained austenite formation by increasing the starting temperature of the martensite and causing the formation of refined martensite laths, which are highly desired during hardfacing 
with martensitic stainless steel, conducting to an enhancement of mechanical properties [25]. In order to prevent the impact of dilution, a thickness of $15 \mathrm{~mm}$ with five layers of deposition is generally practiced [19]. It is to be noted that wear of the top cladding surface not only depends on hardness of the top layer but also on its microstructure [26]. For applications such anti-ballistics, the strength of the weld deposits or weld joints is an important parameter [27] and thus, microstructure plays an important role. Rao et al [28] reported that the long-term exposure of the interface to high temperature will lead to grain coarsening and a brittle interface was found due to cast dendritic structure in the clad [28]. Thus, the interlayer claddings are used to reduce the dilution effect and to enhance wear resistance, hardness etc. However, chances of metallic carbides formation also increases in interlayer claddings [29]. Modern techniques such as explosive cladding and microwave cladding are being used in several manufacturing units. In explosive weld zones, fatigue life varies with temperature of exposure and time of exposure, resulting in grain growth and recrystallization in the sample as well as decarburization occurring at the interface zone [30]. Microwave cladding is one of the most economical and proficient ways of cladding where uniform surface texture and properties can be obtained with uniform heat distribution throughout the clad, with good tribological properties [31].

From the above discussion, it can be observed that many filler materials have been used for cladding process, from austenite stainless steel to martensitic stainless steel. Nonetheless, very limited work on the minimal layer thickness, wear characteristics and microstructural behavior of martensitic welded clads have been reported until now. In this paper, the microstructure, mechanical and tribological properties of AISI 410 (martensite) cladded on EN 8 surface were analyzed. As less brittleness compared to solid-state welding procedures can be achieved by MIG [4], this technique was employed for cladding. Results of pin on disk tribological tests, 3D profilometer, scanning electron microscope (SEM), X-ray diffraction (XRD), and energy dispersive spectroscopy (EDS) analysis are presented, underlining the efficiency of the proposed cladding process.

\section{Experimental Procedures}

\subsection{Sample Preparation and Specification}

Annealed EN 8 (rectangular flat bars) and AISI 410 filler material (spool form) were procured from local market in Chennai, India. The cladding was carried out on the EN 8 base metal parallelepipedal sample of $100 \mathrm{~mm} \times 70 \mathrm{~mm} \times 20 \mathrm{~mm}$ using MIG welding. Argon gas was used during cladding. The cladding was done on surface area of $61 \mathrm{~mm} \times 32 \mathrm{~mm}$. Before the cladding process, the impurities and unevenness on top surface the plate was thoroughly removed by sand papers and pencil grinder. The composition (weight percentage, wt.\%) of the base metal material (uncladded EN 8) and the AISI 410 filler material were analyzed using an optical emission spectroscope (chemical) (OES Foundry Master, WAS, Germany) as per ASTM E 415, being presented in Tables 1 and 2, respectively. The filler material was chosen in order to achieve high wear resistance and hardness of the cladded surface.

Table 1. Composition of EN 8 (wt.\%).

\begin{tabular}{ccccc}
\hline $\mathbf{C}$ & $\mathbf{S i}$ & $\mathbf{M n}$ & $\mathbf{S}$ & $\mathbf{P}$ \\
\hline $0.41 \%$ & $0.35 \%$ & $<1.00 \%$ & $0.06 \%$ & $0.06 \%$ \\
\hline
\end{tabular}

Table 2. Composition of AISI 410 (wt.\%).

\begin{tabular}{ccccccc}
\hline $\mathbf{C}$ & $\mathbf{M n}$ & $\mathbf{S}$ & $\mathbf{P}$ & $\mathbf{S}$ & $\mathbf{C h}$ & $\mathbf{N i}$ \\
\hline$<0.15 \%$ & $<1 \%$ & $<1 \%$ & $0.04 \%$ & $0.03 \%$ & $13.5 \%$ & $0.75 \%$ \\
\hline
\end{tabular}

\subsection{Material Deposition}

The cladding parameters were selected such that a standard medium heat input was achieved. AISI 410 wire $(\Phi 1.2 \mathrm{~mm})$, was used as the filler material. In order to obtain the desired medium heat 
input $(0.55-0.60 \mathrm{~kJ} / \mathrm{mm})$, the cladding was done with an arc current of 110-115 A, arc voltage of $25 \mathrm{~V}$, and welding speed of $4 \mathrm{~mm} / \mathrm{s}$. The heat input (H.I) of $0.55-0.60 \mathrm{~kJ} / \mathrm{mm}$ was chosen in order to get bead height of above $3 \mathrm{~mm}$ with minimum penetration. During the process, it was observed that if the bead or deposition height was below $3 \mathrm{~mm}$ then it was difficult for grinding and making surface flat [32]. The Ador CHAMP MIG400 (Ador: Chennai, India) was used to conduct the cladding process. After the first weld deposition, the surface of the weld deposit was hand grinded to get a flat upper surface for the next deposition. The first deposition thickness was maintained at $3 \mathrm{~mm}$, after hand grinding. Repeated welding and grinding were carried out for two more times and the thickness achieved for those two layers were 3 and $4 \mathrm{~mm}$, respectively, making the total weld deposition thickness of $10 \mathrm{~mm}$ (Figure 1a) on the substrate of $20 \mathrm{~mm}$ thickness. A typical weld cladding done in this work have been shown in Figure 1b. In order to minimize the dilution from the substrate to the top layer, the heat input and the deposition thickness were kept at the medium level and constant, respectively.

(a)

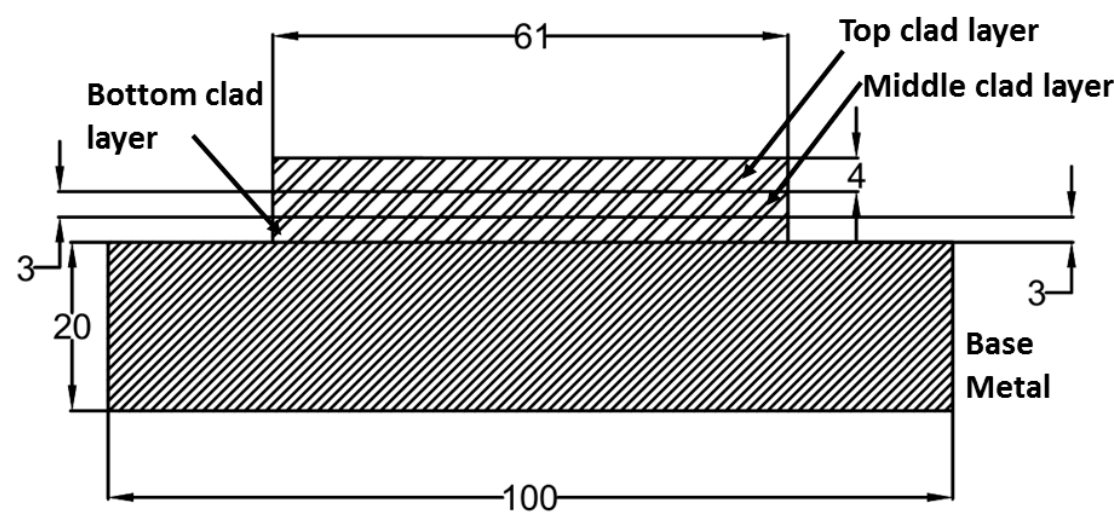

Scale 1:1 All dimensions are in millimetre $(\mathrm{mm})$

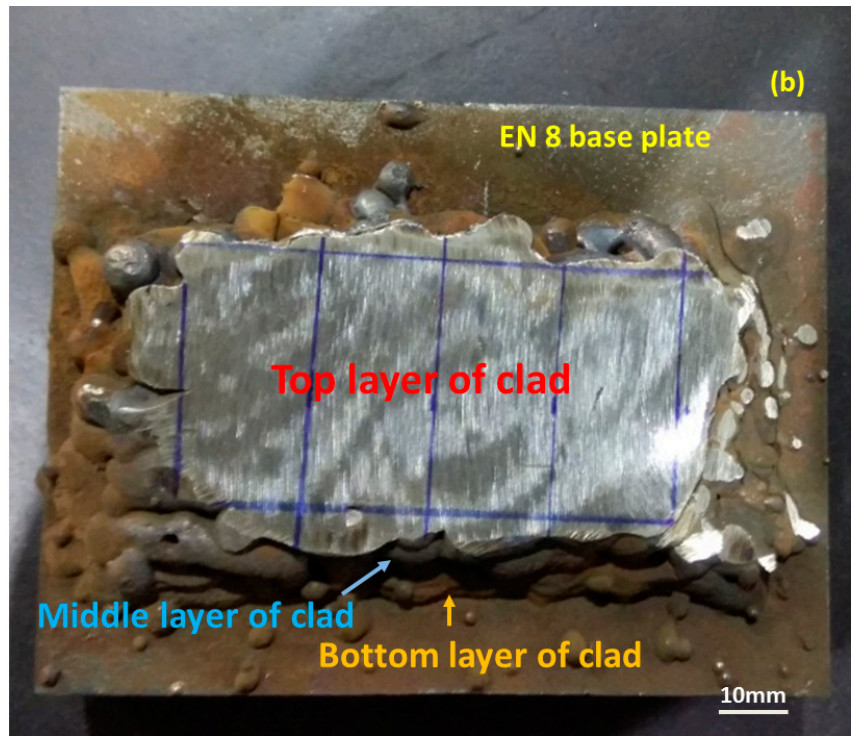

Figure 1. (a) Schematic representation of layer thickness. (b) Cladding on EN 8 substrate.

\subsection{Metallographic Analysis}

A small specimen from the cladded plate was extracted for the metallographic analysis of three weld layers and dilution. The extracted specimen were grinded with different grades of emery paper (such as grit 120, 180, 240, 300, 400, 600, 800, 1000, and 1200) followed by cloth polishing with diamond paste of $0.15 \mu \mathrm{m}$. Then the specimen was etched with Kalling's reagent for nearly $10 \mathrm{~s}$ and immediately 
rinsed with acetone to identify the weld layers. The light microscope (Olympus: Tokyo, Japan) and the scanning electron microscope (SEM) (FEI Quanta FEG 200: Eindhoven, Netherlands) were used to identify the layers and dilution zones. The energy dispersive spectroscopy (EDS) was carried out on the specimen to understand the depth of carbon diffusion from the substrate. The grain size was measured across the top surface of the cladded plate to the substrate using line intercept method following a scale 1:1 [33]. In to use this method the micrograph was imported in AutoCAD 2017 software (N 52.0.0, Chennai, India). A random line was drawn using the drafting tools in AutoCAD software after scaling to 1:1. After the one was drawn, the number of grain boundaries intersecting the lines were counted. The average grain size was found by dividing the number of intersections with the actual length of the line.

A separate specimen of $15 \mathrm{~mm} \times 4 \mathrm{~mm} \times 2 \mathrm{~mm}$ was extracted for the X-ray diffraction (XRD) (Bruker, D8 Advance, Billerica, Massachusetts, USA) to identify the major phase fractions at weld deposits. The phase fraction was determined by considering $\mathrm{d}$ values from the peak intensity and corresponding $2 \theta$ values. The data base of the JCPDS (Joint Committee on Powder Diffraction Standards) was used to confirm the phases. The working principle of the XRD measurement is mainly based on the famous Brag's law, i.e., $\mathrm{n} \lambda=2 \mathrm{~d} \sin \theta$ ( $\mathrm{n}=$ order of fringe, $\lambda=$ wavelength of ray, $\mathrm{d}=$ lattice distance, $\theta=$ glancing angle.

\subsection{Hardness Test}

The hardness test of all the cladded layers was performed using Rockwell hardness testing machine (Fuel Instrument \& Engineers Pvt. Ltd. YADRA, India). A conical base diamond indenter with tip including angle of $120^{\circ}$ was used and $100 \mathrm{Kgf}$ static load was applied for $10 \mathrm{~s}$ on each layer during the test. The test was repeated four times on each layer and the average of all the readings have been reported in this work.

\subsection{Wear Test}

The anti-wear properties of the cladded pins were investigated using a pin on disc tribometer (DUCOM, TR100, Bengaluru, India). Cylindrical pins of $10 \mathrm{~mm}$ diameter pins and height $30 \mathrm{~mm}$ were made from the cladded plate as shown in Figure 2. The counter surface to these cladded pins was an EN 31 disc with hardness 58-60 HRC which was rotated at $500 \mathrm{rpm}$. A normal load of $100 \mathrm{~N}$, (contact pressure $1.273 \mathrm{~N} / \mathrm{mm}^{2}$ ) was applied on the pin. The tests were carried for $3600 \mathrm{~s}$. The coefficient of friction and wear rate reported in the work are the average of three readings and were automatically calculated by the software of the tribometer (V 1.0.0, WINDUCOM, Bengaluru, India). In order to understand the severity of the wear, the surface of the pins were analyzed using a scanning electron microscope (SEM) and a 3D surface profilometer (Taylor Hobson, Leicester, UK).

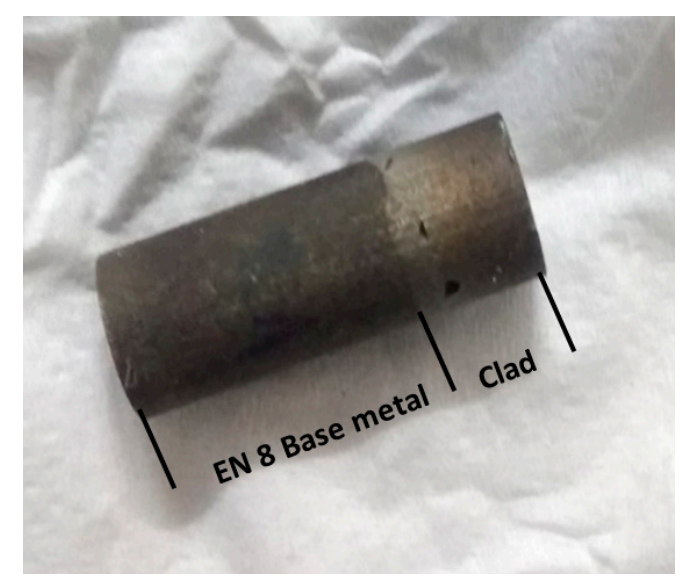

Figure 2. Pin used in pin on disc for wear test. 


\section{Results and Discussion}

\subsection{Metallographic Analysis and Hardness}

Figure 3a shows the microstructure of the base metal, medium carbon steel (EN 8), where discrete pearlitic structures (black spots) are visible on the ferritic matrix. The base metal microstructure is primarily $(\sim 90 \%)$ dominated by $\alpha$ phase at annealed condition. Figure $3 \mathrm{~b}$ shows the top layer which was partially reheated during the deposition of adjacent passes in the same layer. The grain size was measured using line intercept method after proper scaling (1:1) of the microstructural images [33]. The carbon percentage of AISI 410 (top layer) is suitable for the formation of lath martensite [34], hence the microstructure showed the presence of the lath martensite transformed from austenite during cooling. As welding passes were drawn consecutively at the top layer, this resulted in slow cooling, which allowed more time for grain growth and resulted in $\sim 4 \mu \mathrm{m}$ of coarser grain (Table 3 ). The middle layer (Figure 3c) was a reheated zone having semi-equiaxed grains of $\sim 2 \mu \mathrm{m}$. The middle layer grain sizes were approximately two times smaller than the top layer, as shown in Table 3. The middle layer was subjected to continuous thermal stress from both the top and bottom layers resulting in heterogeneous stress distribution. Additionally, the cooling in the middle layer was comparatively faster compared to the top layer because the heat coming from the top layer was easily escaped to the colder bottom layer and prevented coarsening of the grain. Therefore, the prior austenitic morphology was changed from columnar to equiaxed due to reheating of the deposited layer.

Table 3. Grain size (average) of the top, middle, and bottom layer of cladding and of the base metal.

\begin{tabular}{cc}
\hline Layer & Average Grain Size $(\mu \mathrm{m})$ \\
\hline Top & $3.42 \pm 1.13$ \\
Middle & $2.10 \pm 0.92$ \\
Bottom & $4.03 \pm 0.59$ \\
Base metal & $5.02 \pm 1.37$ \\
\hline
\end{tabular}
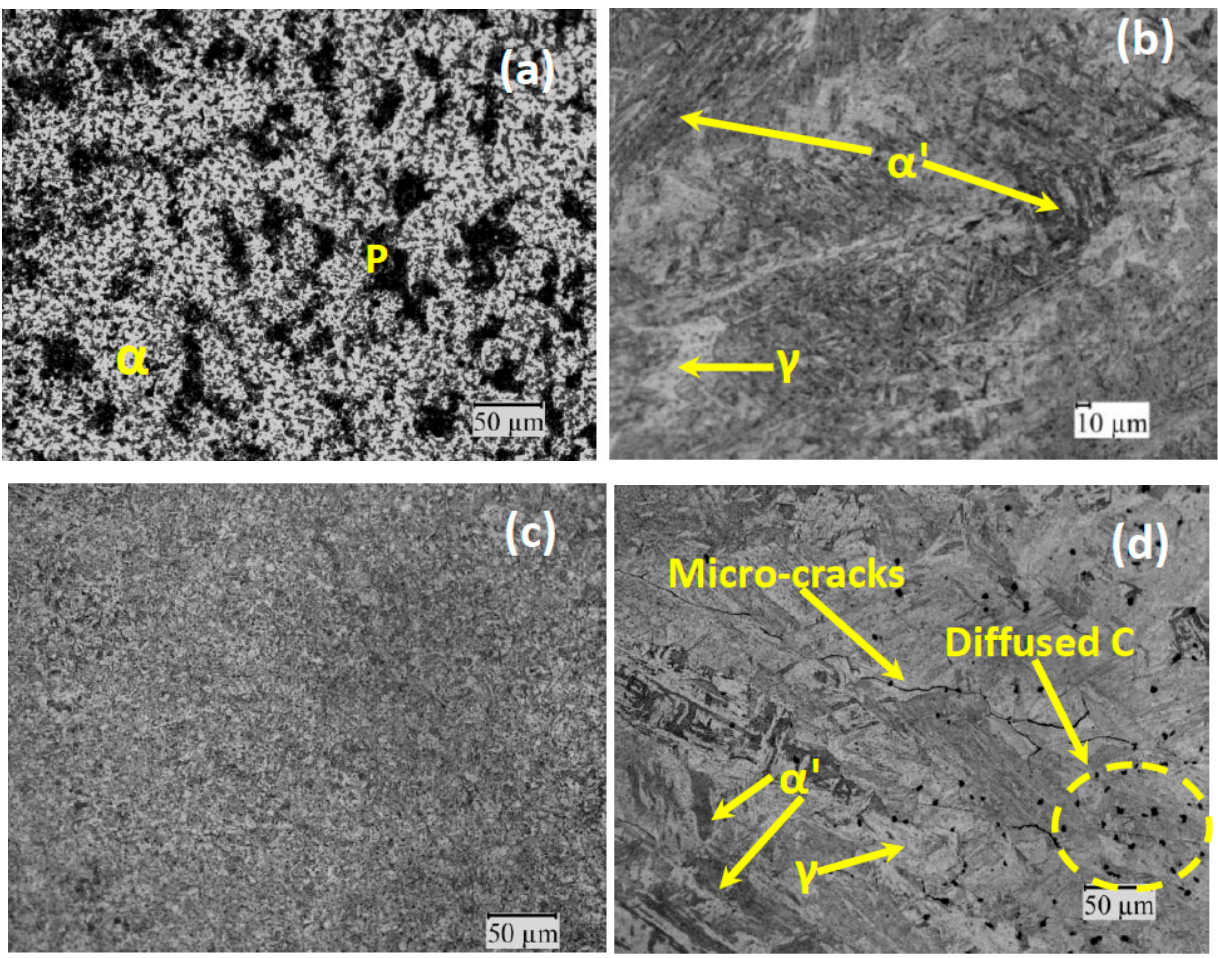

Figure 3. Cont. 

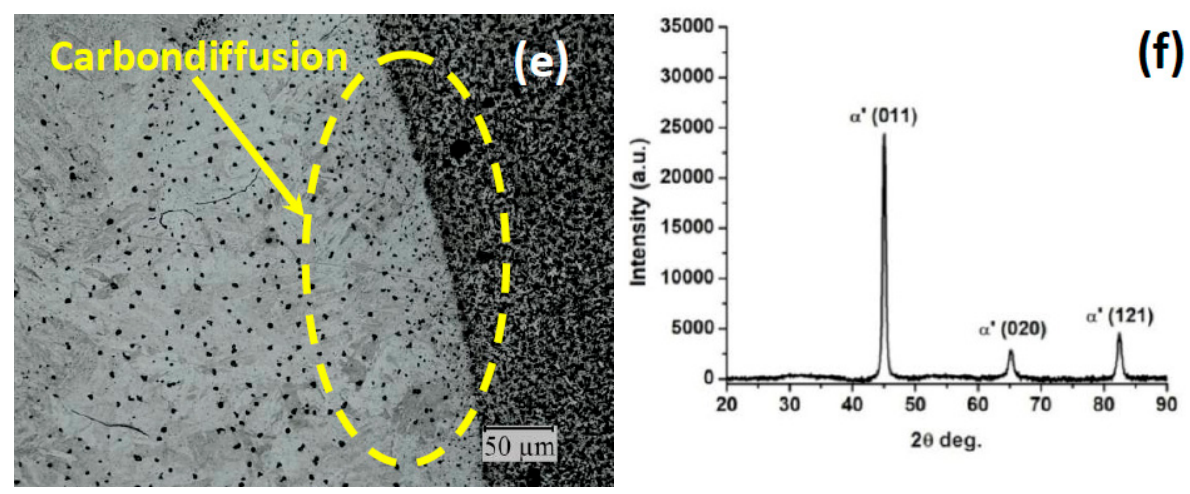

Figure 3. Microstructure of: (a) EN 8 without clad; (b) retained austenite (lath martensite and whitish spots); (c) middle layer of the clad with refined grains; (d) bottom layer of the clad carbon diffusion;

(e) fusion zone of clad and base metal; and (f) XRD analysis of top layer showing presence of martensite.

The bottom layer microstructure, presented in Figure $3 \mathrm{~d}$ and e, showed normally larger grain structure, martensite, and traces of austenite. The presence of larger grains was due to the diffusion of carbon from base plate, which enhanced the stability of austenite at higher temperature and restricted the grain refinement on cooling. Furthermore, the presence of high carbon with $12-13 \%$ of chromium was likely to cause precipitation of metal $(\mathrm{M})$ carbides. The $\mathrm{M}_{23} \mathrm{C}_{6}$ type of carbide is the most common at the temperature between $950-1050{ }^{\circ} \mathrm{C}$ [35-37], as also observed from the micrograph in Figure $3 \mathrm{~d}$, and it was seen that the bottom layer had higher fraction of carbon that led to the formation of carbides. This formation of carbides, in spite of having larger grains than top layer and the bottom layer, resulted in higher average hardness. The rapid dissipation of heat through the base metal did not allow sufficient time of alloy segregation and solid-solution, which might be a probable cause of carbide precipitation. XRD analysis of the top layer, shown in Figure 3f, revealed the presence of martensite as the major phase fraction. Martensite has body centric tetragonal structure and is a super saturated form of carbon with high bond energy [38].

The SEM analysis of the cladded and uncladded EN 8 (base metal) samples also showed the presence of martensite lath structures in cladded layers and ferritic-pearlitic structure in base plate, as shown in Figure 4a-d. The EDS element mapping of bottom layer around fusion boundary depicted strong evidence of carbon diffusion across the boundary in the fusion zone (Figure 5). The carbon diffusion at the bottom layer was reached up to $\sim 30-40 \%$, however, this diffusion of carbon was exceptionally reduced at the middle and top layers due to the pre-deposition grinding of several millimeters. It was observed that the top layer had minimum carbon diffusion of $\sim 3-5 \%$ only.

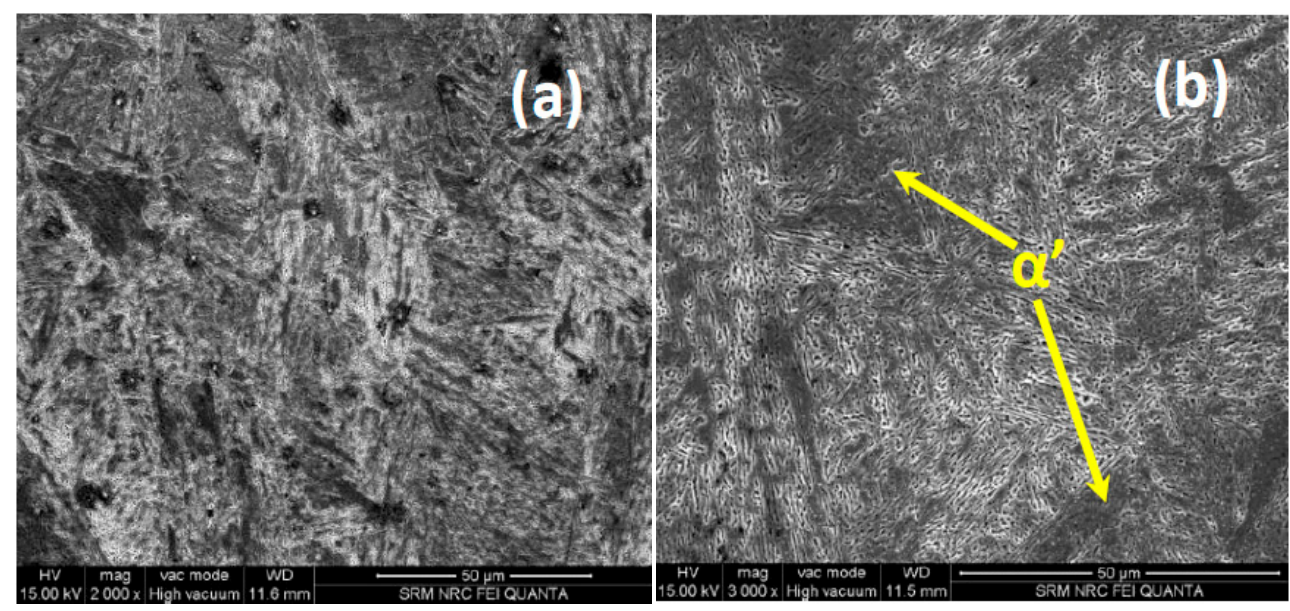

Figure 4. Cont. 

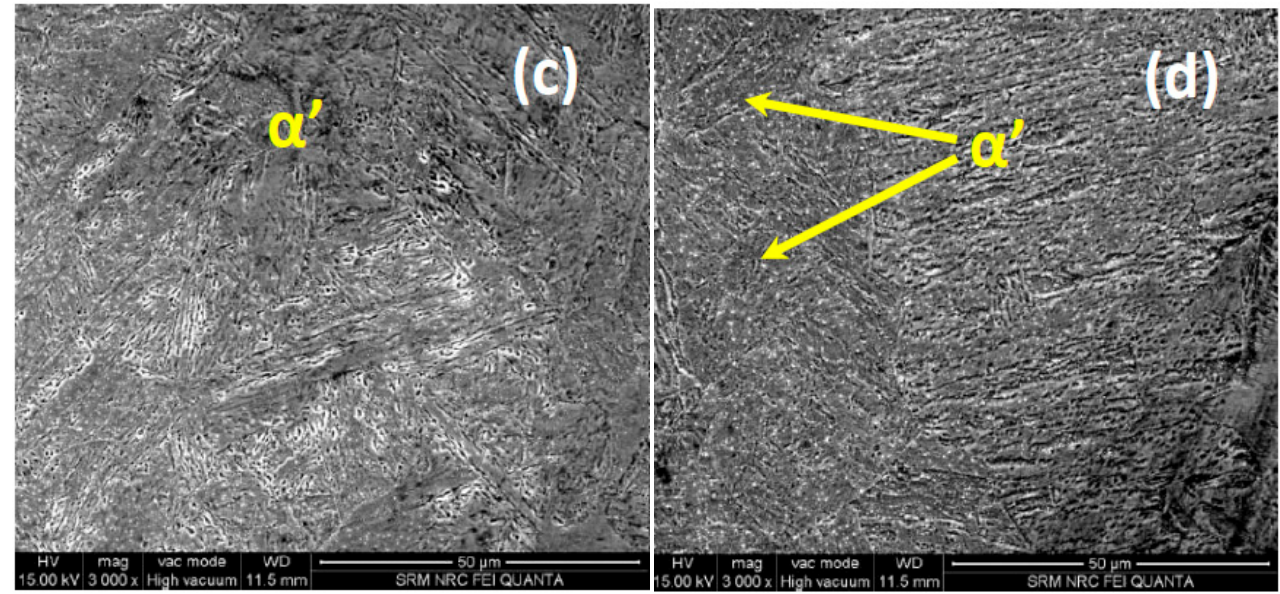

Figure 4. Scanning electron microscope (SEM) images of (a) EN 8 without clad; (b) retained austenite (lath martensite and whitish spots); (c) middle layer of the clad with refined grains; and (d) bottom layer of the clad carbon diffusion.

The bottom layer of the cladding has large carbon diffusion of up to $30 \%$ in places, as calculated from the SEM-EDS analysis is shown in Figure 5. The micrographs of bottom layer (Figure 3d) also depict the formation of micro-cracks oriented towards the middle layer due to the high thermal stress generated from the consecutive passes and partial entrapment of hydrogen [35]. The fast heat dissipation from the bottom layer is probably the cause of hydrogen entrapment within the molten pool, enhancing the cracking susceptibility of the cladded layer [35].
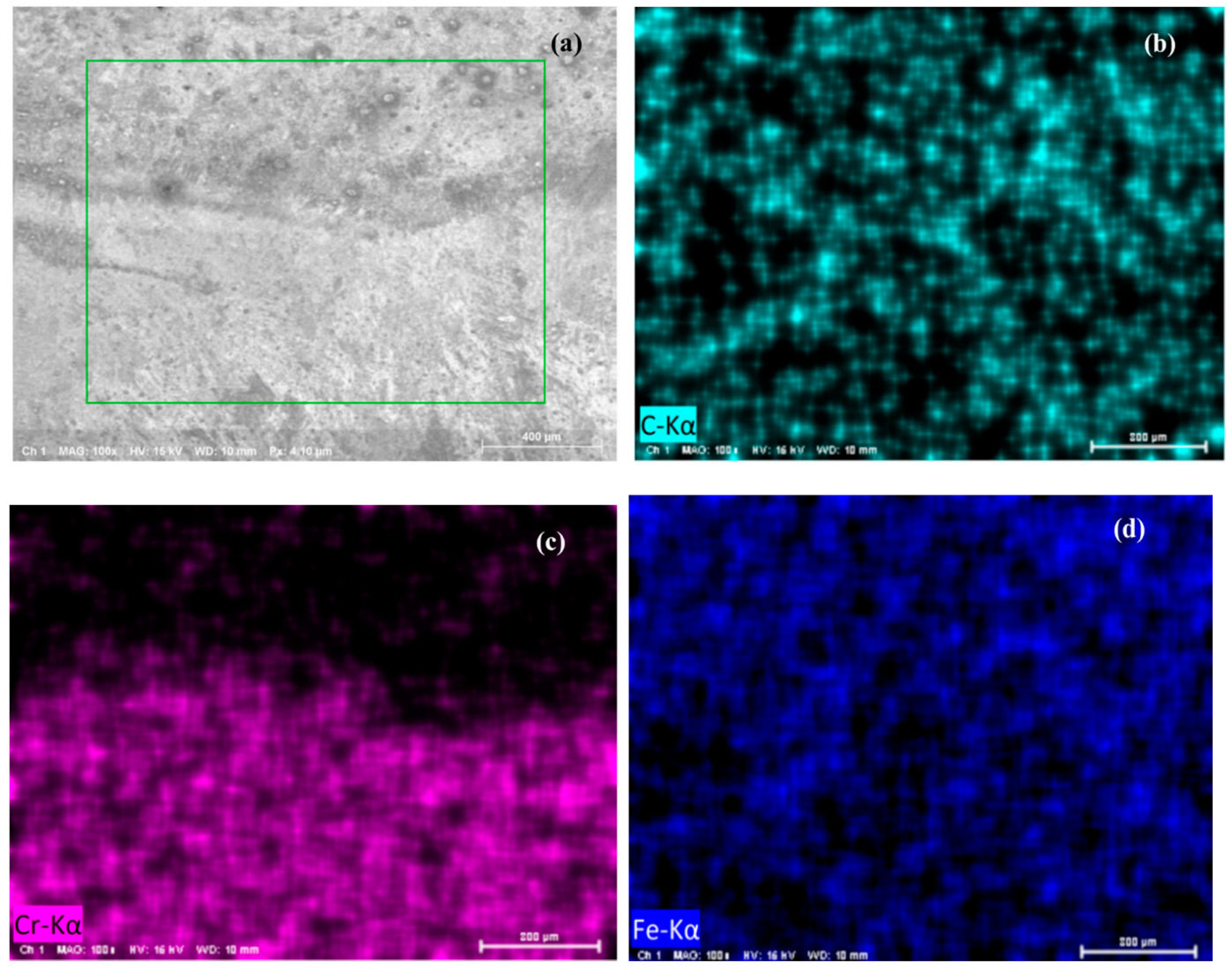

Figure 5. Cont. 

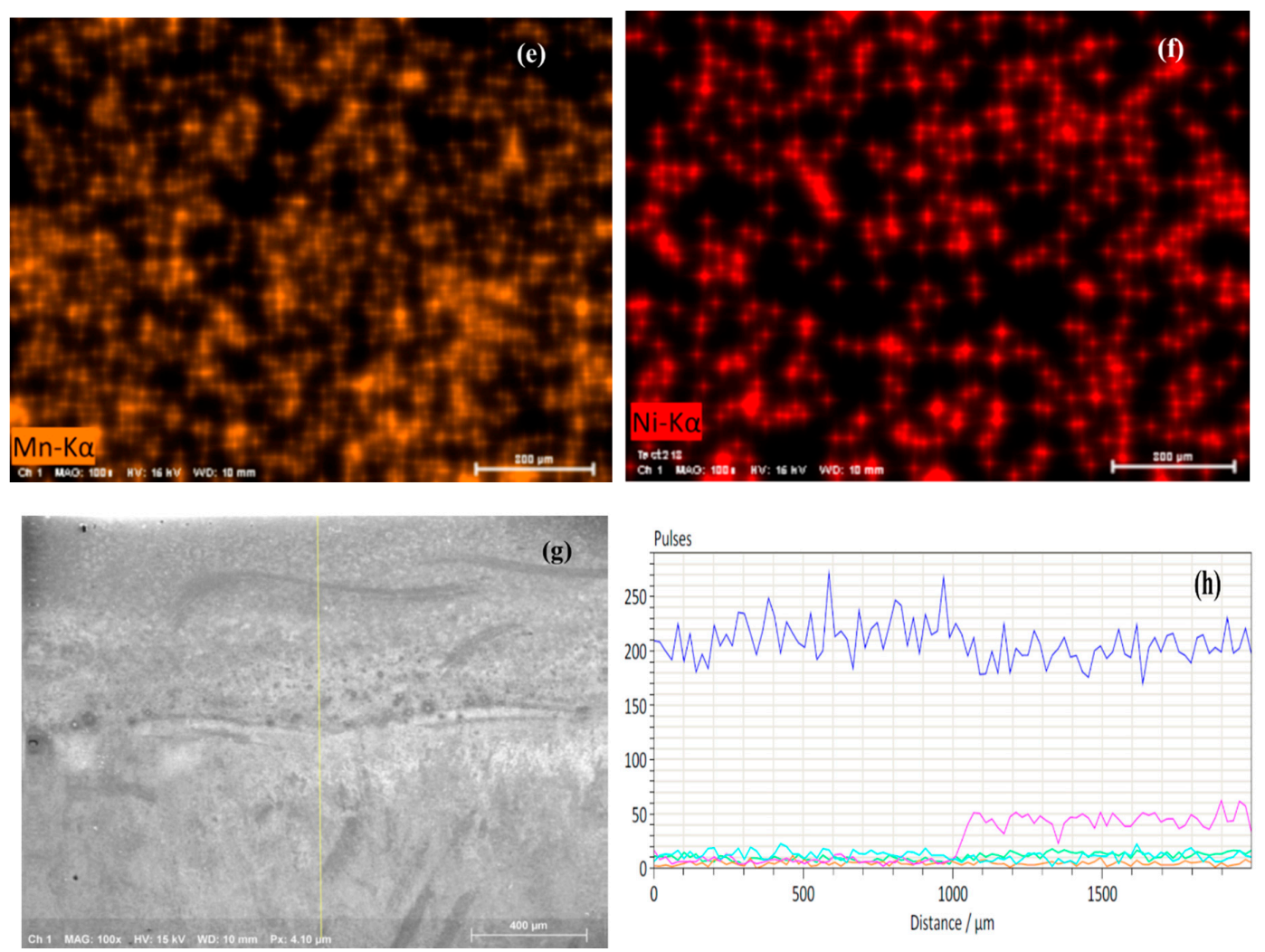

Figure 5. Energy dispersive spectroscopy (EDS) elemental map of bottom layer fusion boundary (a) area scan of bottom layer and substrate $(\mathbf{b}-\mathbf{f})$ elemental distribution during scanning (Carbon $(C)$, Chromium (Cr), Iron (Fe),Manganese (Mn), Nickel(Ni)) (g) line scan of bottom layer and substrate (h) plot of pulse generation by each element (see Supplementary Materials section).

Table 4 exhibits the hardness of each layer of the clad. Compared with base metal (uncladded EN 8) sample (22-23 HRC), the clads exhibited higher hardness. Among all the layers, the middle layer displayed the highest hardness. Compared to the base metal, the higher hardness of top and bottom layer is probably due to the presence of martensitic phase with small amount of retained austenite. In addition to the appearance of these phases, the hardness of the bottom layer often depends on the presence of precipitated carbides resulted from base metal dilution. The hardness of the cladded layers is also dependent on the average grain size and can be estimated by the Hall-Petch equation:

$$
H_{V}=H_{o}+\frac{K_{y}}{\sqrt{d}}
$$

where, $H_{v}=$ average hardness value, $H_{o}=$ material constant, $K_{y}=$ coefficient, and $d=$ average grain size $(\mu \mathrm{m})$.

Table 4. Hardness of different layers of clad.

\begin{tabular}{cc}
\hline Layer of Clad & Hardness (HRC) \\
\hline Top layer of clad & $51.5 \pm 2.35$ \\
Middle layer of clad & $58 \pm 0.6$ \\
Bottom layer of clad & $53 \pm 2.17$ \\
Base metal & $23 \pm 1.2$ \\
\hline
\end{tabular}

From Table 3, it was seen that the middle layer had the least average grain size and thus resulted in the highest hardness (Table 4). Similar trend of hardness results were also reported earlier [39]. 
Figure 6 shows that the grain size is inversely proportional to hardness and thus, the layer hardness increased with decreasing grain size. Relatively larger grain size and traces of retained austenite reduced the extreme brittleness and induced slight ductility in the top and bottom layers $[40,41]$. Nevertheless, the top layer maintained good hardness due to the presence of martensite. The middle layer (Figure 3c) showed highest hardness due to its refined martensite grain structure. In spite of having larger grains in bottom layer due to carbon diffusion from base metal, which in turn resulted in carbide formation, the bottom layer exhibited higher average hardness value than the top layer.

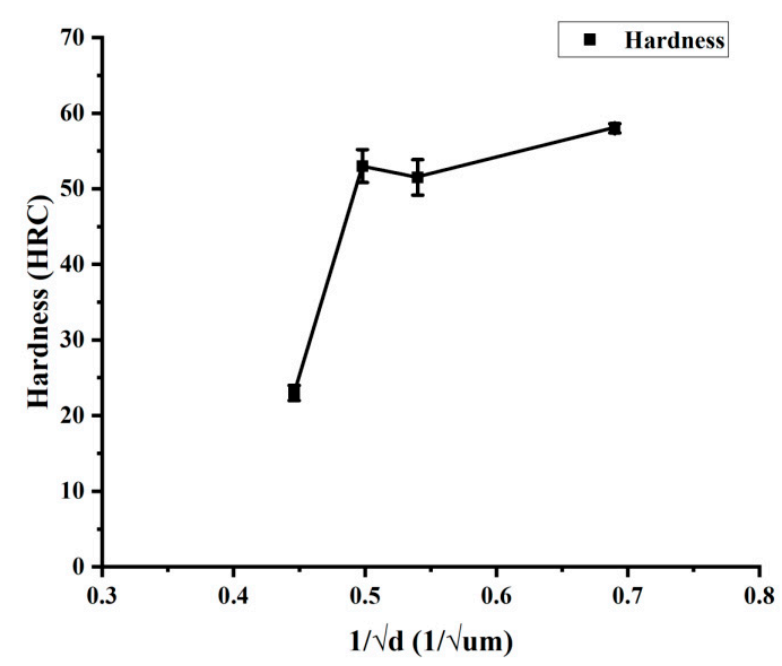

Figure 6. Hall-Petch curve showing the relationship between hardness and average grain size.

\subsection{Investigating the Wear Properties of the Clad}

The wear test was conducted using a pin on disc tribometer (DUCOM, Bengaluru, India). During the tribo test, it has been observed that EN 8 pin (base metal) without any clad failed within 475-500 s whereas the cladded EN 8 pin ran up to 3600 s, as shown by the plot in Figure 7a. The failure of the pin was noticed with high wear rate resulting in high vibration of the pin holder and ultimately tipping the tribometer. The wear rate of uncladded EN 8 was found to be $0.0003 \mathrm{~mm}^{3} / \mathrm{Nm}$ within a short period of time ( $478 \mathrm{~s}$ ) whereas, the cladded EN 8 was found to be $0.00011 \mathrm{~mm}^{3} / \mathrm{Nm}$ in $3600 \mathrm{~s}$. The cladded pin sample ran smoothly for $3600 \mathrm{~s}$ without any kind of vibration and tipping of the tribometer, indicating the occurrence of normal wear. Figure $7 \mathrm{~b}$ exhibits the better wear resistance of the cladded pins as compared to the base metal (EN 8 uncladded). Furthermore, the cladded EN 8 pin lasted about nine times longer than the uncladded EN 8 pin. Even after $3600 \mathrm{~s}$ of run time the cladded pin did not completely failed, whereas the scar depth of base metal was found to be much higher for $478 \mathrm{~s}$. 

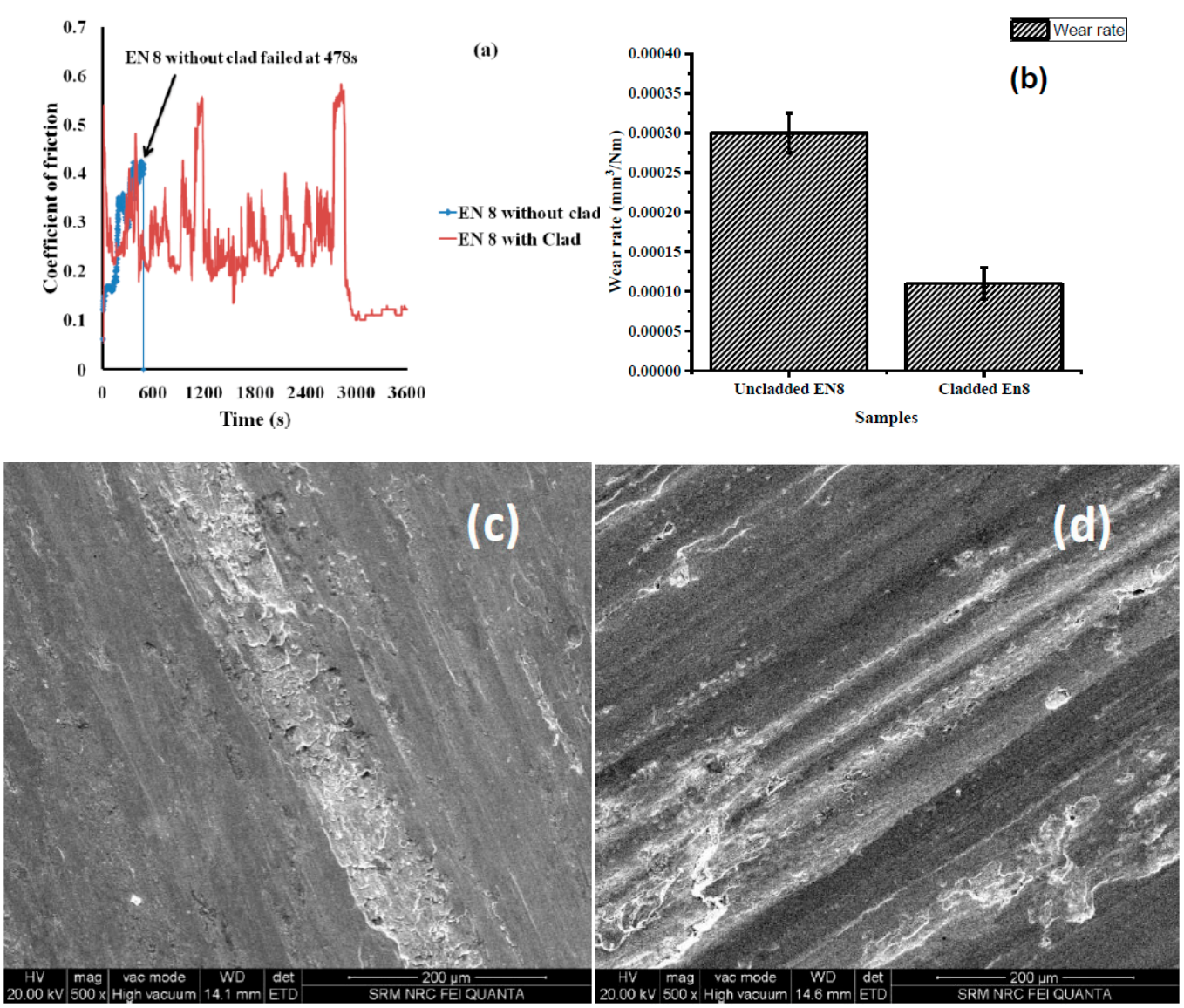

Figure 7. (a) Experimental reading showing failure of uncladded EN 8 (base metal) pin. (b) Wear rate comparison graph between cladded and uncladded EN 8. (c) SEM image of pin surface of uncladded EN 8 after 478 s. (d) SEM image of pin surface of cladded EN 8 after $3600 \mathrm{~s}$.

The Scanning electron microscope images presented in Figure $7 \mathrm{c}$ and $\mathrm{d}$ shows grooves on the surfaces of the uncladded and cladded pins. It is to be noted that the surface shown in Figure 7c is not the actual surface of the pin which was in contact with EN 31 disc. This surface is the left-over surface of the pin. The base metal (uncladded EN 8) pin broke after $478 \mathrm{~s}$ and the left-over surface seems to have undergone a polishing effect. The failure was so catastrophic that portion of the pin which was out of the pin holder wore rapidly and the left-over surface inside the holder was taken for analyzing the wear. On other hand, the cladded EN 8 ran for 3600 s indicating high durability of the clads. As the tests were conducted under dry condition, the resultant wear mechanism was a combination of both adhesion and ploughing [42]. Grooves and galling were observed in both cladded and uncladded surfaces, indicating adhesion and ploughing wear mechanisms involved during the tribotest. The 3D surface characteristics of both uncladded and cladded EN 8 also indicated high wear in the uncladded leftover pin surface (Figures 8 and 9). 

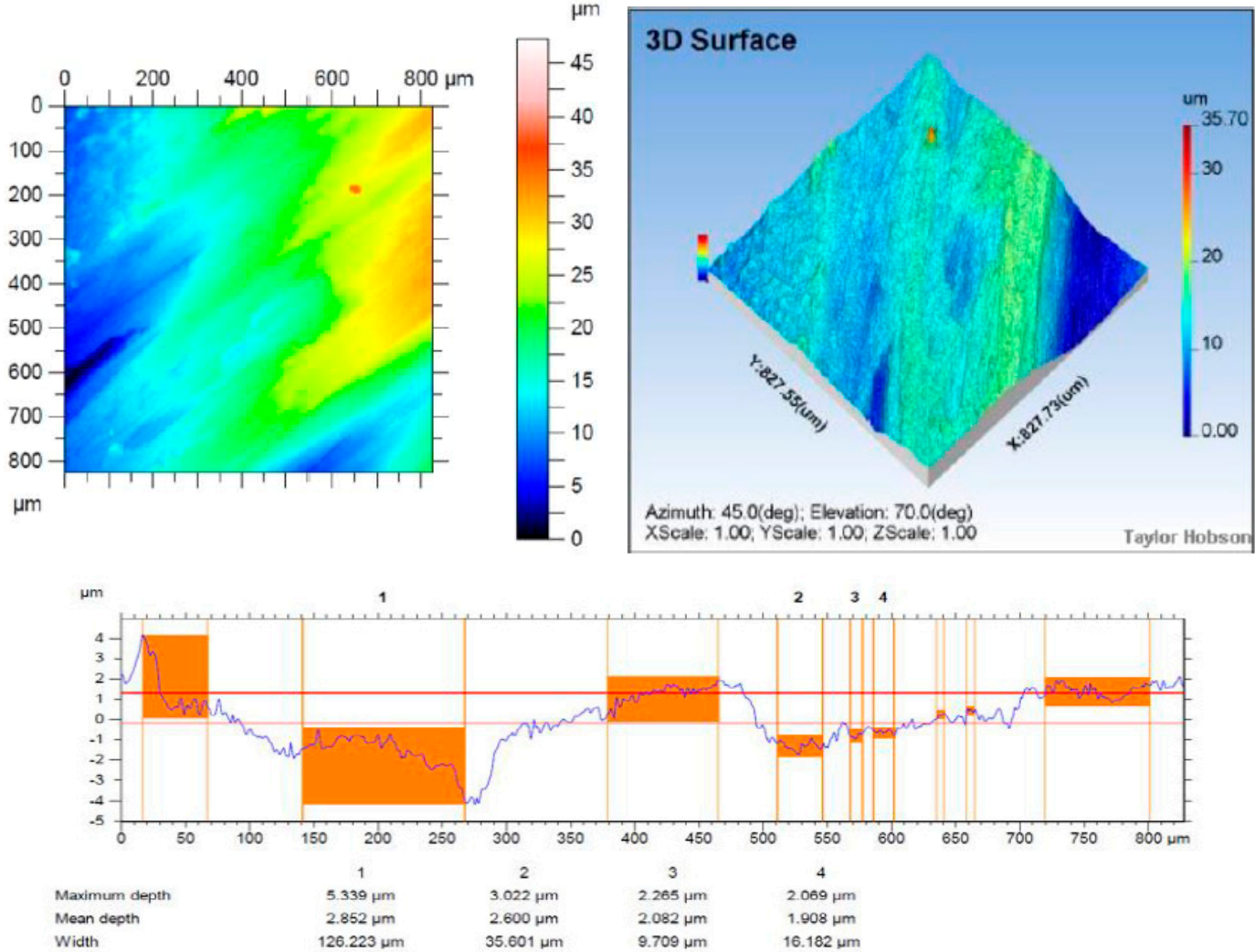

Figure 8. 3D laser profiling of the base metal (uncladded EN 8) pin after pin on disc.
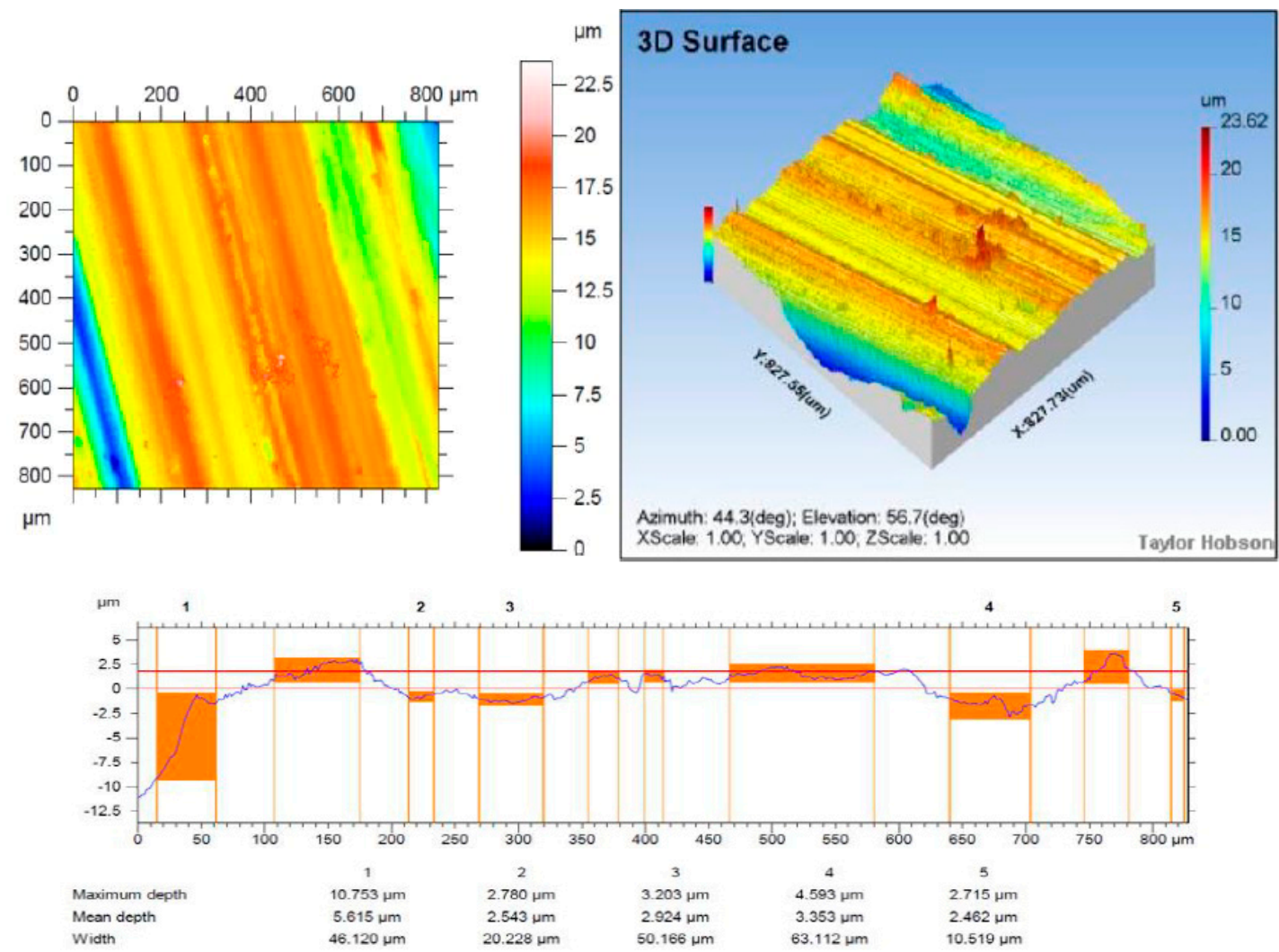

Figure 9. 3D laser profiling of AISI 410 cladded EN 8 pin after pin on disc. 
The average scar width and depth of uncladded and cladded surfaces were calculated from the results of texture analysis and represented in Table 5. The scar width of the cladded specimen is significantly lower than the uncladded EN 8 even after $3600 \mathrm{~s}$ of sliding time. However, due to higher sliding time of the cladded specimen, the scar depth is $\sim 1 \mu \mathrm{m}$ higher than the uncladded specimen.

Table 5. Wear scar dimensions of base metal and cladded specimens.

\begin{tabular}{ccc}
\hline Element & Average Scar Width $(\mu \mathrm{m})$ & Average Scar Depth $(\mu \mathrm{m})$ \\
\hline Base metal (uncladded) (after 478 s) & $46.93 \pm 11.01$ & $2.360 \pm 0.38$ \\
AISI 410 cladded sample (after 3600 s) & $38.03 \pm 19.57$ & $3.379 \pm 0.35$ \\
\hline
\end{tabular}

The volumetric loss of the cladded and uncladded specimens were calculated using the Archard equation as given below.

$$
V=K(S N) / H
$$

where, $V=$ volumetric loss, $K=$ constant $S=$ sliding distance, $N=$ normal load, and $H=$ hardness of pin.

$$
V=k S N
$$

where, $k=$ specific wear rate $(K / H)$.

The volumetric loss for uncladded EN 8 (base metal) was found to be $48.80 \mathrm{~mm}^{3}$ for $\mathrm{S}=1.626 \mathrm{~km}$ and $\mathrm{N}=100 \mathrm{~N}$. Similarly, the volumetric loss for cladded EN 8 was found to be $134.774 \mathrm{~mm}^{3}$ for $\mathrm{S}=12.252 \mathrm{~km}$ at same applied load. For same sliding time of $478 \mathrm{~s}$, the volumetric loss of the cladded specimen was significantly lower than the base metal (uncladded EN 8) specimen as shown in Table 6 . The graph has been plotted between volumetric loss of cladded EN 8 and Speed-normal load(SN) at different time intervals, shown in Figure 10a. The graph was found to be a straight line, which is in line with other authors [43].

Table 6. Volumetric loss using Archard equation at sliding time of $478 \mathrm{~s}$.

\begin{tabular}{cc}
\hline Element & Volumetric Loss $\left(\mathrm{mm}^{\mathbf{3}}\right)$ \\
\hline Base metal & 48.80 \\
AISI $410 \mathrm{clad}$ & 17.9 \\
\hline
\end{tabular}
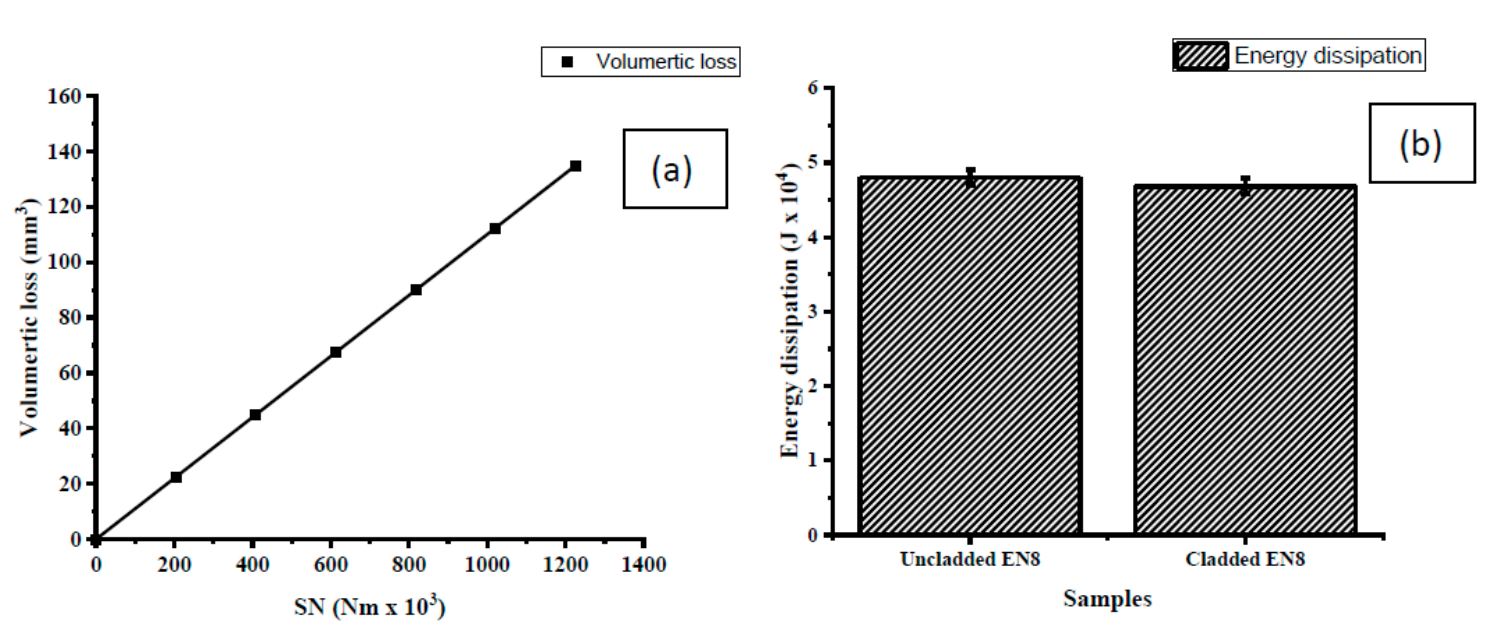

Figure 10. (a)Volumetric loss vs. Speed-normal load SN curve of AISI-410 Clad (based on Archard analysis) after each $600 \mathrm{~s}$ of test till $3600 \mathrm{~s}$, and (b) Bar plot showing energy dissipation uncladded EN 8 (base metal) and AISI 410 cladded EN8 samples. 
The ratio of volumetric loss of base metal to that of clad was calculated by Archard equation (Equation (2)). The energy dissipation was also calculated, using Equation (4).

$$
\Delta E=\int_{0}^{\Delta t} F d x=\int_{0}^{\Delta t} F v d t=F_{a v g .} . \Delta t
$$

where, $\Delta E=$ energy dissipation, $F=$ force, $\Delta t=$ time interval, $v=$ velocity, and $F_{a v g} .=$ mean force.

The energy dissipation value for the cladded pin was $30.497 \times 10^{4} \mathrm{~J}$ after $3600 \mathrm{~s}$, while the total energy dissipation for base metal was found to be $4.803 \times 10^{4} \mathrm{~J}$ after $478 \mathrm{~s}$. Comparing the energy dissipation of base metal EN 8 (uncladded) with the energy dissipation value for cladded material after the same period of $478 \mathrm{~s}$, it was found to be lesser for cladded material (Figure 10b), indicating that AISI 410 cladded material possessed superior wear resistance properties than uncladded EN 8 sample.

\section{Conclusions}

The microstructure, mechanical and tribological properties of AISI 410 (martensite) cladded on EN 8 surface were analyzed. Results of hardness, pin on disk tribological tests (friction coefficient and energy dissipation), 3D profilometry (wear rate and volumetric loss), scanning electron microscopy (SEM), $\mathrm{X}$-ray diffraction (XRD), and EDS analysis underlined the efficiency of the proposed cladding process.

The results exhibited that cladded layers had maximum hardness of about $58 \mathrm{HRC}$ in the middle layer, due to the presence of hard martensite phase, the middle clad layer being a reheated zone. Due to the presence of retained austenite, there was a slight decrease in the hardness of the top layer (49-53 HRC). The XRD results indicated the presence of martensitic phase too. In spite of having larger grain size, the average hardness of bottom layer $(52-55$ HRC) was slightly higher than the top layer due to the presence of metal carbides resulted from the carbon diffusion from base metal.

The average grain size of top and middle layer was between $2-3.5 \mu \mathrm{m}$, while the base metal showed $5.02 \mu \mathrm{m}$ grain size, resulting in higher hardness of clad layers than base metal.

Some micro cracks were also observed in the bottom clad layers, generated by high thermal stresses, multiple passes, and partial entrapment of hydrogen. The bottom layer was the fusion zone of two different metals with different thermal coefficient of expansion, increasing the chances of crack generation. The EDS mapping also showed high diffusion of carbon (30-40\%) in the bottom layer, which reduced to $3-4 \%$ in the top most layer as multiple passes and layers were deposited.

The volumetric wear loss from Archard's equation was found to be $48.80 \mathrm{~mm}^{3}$ for uncladded EN 8 (base metal) and $17.90 \mathrm{~mm}^{3}$ for AISI 410 cladded EN 8. The wear analysis through energy dissipation exhibited that the cladded EN 8 absorbed $30.497 \times 10^{4} \mathrm{~J}$ of energy and did not fail, whereas the uncladded EN 8 was able to absorb only $4.803 \times 10^{4} \mathrm{~J}$ of energy before failure.

The scanning electron microscope and 3D profilometer images exhibited ploughing and galling to be the main wear mechanisms, and the wear tests revealed better wear resistance of the cladded pins as compared to the uncladded pins. The wear rate after cladding reduced by almost three times as compared to the uncladded part.

Supplementary Materials: The following EDS analysis images are available online at http://www.mdpi.com/ 2075-4701/10/7/958/s1, as follows: File1: Area scan of bottom layer \& substrate.pdf; File 2: Line scan of bottom layer \& substrate.pdf; File 3: Line scan of middle \& bottom layer of clad.pdf; File 4: Point analysis and elemental distribution of middle \& bottom layer.pdf.

Author Contributions: Conceptualization, M.M., S.B., and V.P.; methodology, M.M., S.B., and V.P.; investigation, M.M., S.B., V.P., P.S., and A.N.; data curation, S.B., P.S., and A.N.; supervision and project administration, M.M. and S.B.; writing—original draft preparation, P.S. and A.N.; writing—review and editing, S.B., M.M., and V.P. All authors have read and agreed to the published version of the manuscript.

Funding: The research received no external funding.

Acknowledgments: The authors acknowledge the Centre for Advanced Manufacturing and Metrology, CSIR-Central Mechanical Engineering Research Institute, Government of India, Durgapur, West Bengal, 713209 and Tribology and Surface Interaction Research Laboratory, SRM Institute of Science and Technology, Kattankulathur, Tamil Nadu 603203 for the facilities provided during the project. 
Conflicts of Interest: The authors declare no conflict of interest.

\section{References}

1. Saha, M.K.; Das, S. Gas Metal Arc Weld Cladding and its Anti-Corrosive Performance-A Brief Review. Athens J. Technol. Eng. 2018, 5, 155-174. [CrossRef]

2. Xi, Y.; Liu, D.; Han, D. Improvement of corrosion and wear resistances of AISI 420 martensitic stainless steel using plasma nitriding at low temperature. Surf. Coat. Technol. 2008, 202, 2577-2583. [CrossRef]

3. Lippold, J.C.; Kotecki, D.J. Welding Metallurgy and Weldability of Stainless Steels; Wiley-Interscience: Hoboken, NJ, USA, 2005.

4. Puli, R.; Janaki Ram, G.D. Wear and corrosion performance of AISI 410 martensitic stainless steel coatings produced using friction surfacing and manual metal arc welding. Surf. Coat. Technol. 2012, 209, 1-7. [CrossRef]

5. Khadadad, A.; Koçak, M.; Ventzke, V. Mechanical and fracture characterization of a bi-material steel plate. Int. J. Press. Vessels Piping 2002, 79, 181-191. [CrossRef]

6. Lee, J.E.; Bae, D.H.; Chung, W.S.; Kima, K.H.; Lee, J.H.; Cho, Y.R. Effects of annealing on the mechanical and interface properties of stainless steel/aluminum/copper clad-metal sheets. J. Mater. Proc. Technol. 2007, 187-188, 546-549. [CrossRef]

7. Lee, K.S.; Yoon, D.H.; Lee, S.E.; Lee, Y.S. The effect of thermomechanical treatment on the interface microstructure and local mechanical properties of roll bonded pure Ti/439 stainless steel multilayered materials. Procedia Eng. 2011, 10, 3467-3472. [CrossRef]

8. Kaushal, S.; Sirohi, V.; Gupta, D.; Bhowmick, H.; Singh, S. Processing and characterization of composite cladding through microwave heating on martensitic steel. J. Mater. Des. Appl. 2018, 232, 80-86. [CrossRef]

9. Olson, D.L.; Siewert, T.A.; Liu, S.; Edwards, G.R. Metals handbook. Welding, brazing and soldering, 9th ed.; ASM: Metals Park, OH, USA, 1983.

10. Lucas, W. Arc Surfacing and Cladding Processes to Enhance Performance in Service and to Repair Worn Components. Weld. Met. Fabric. 1994, 62, 55-60.

11. Sreeraj, P.; Kannan, T. Modeling and prediction of stainless steel clad bead geometry deposited by GMAW using regression and Artificial Neural Network. Adv. Mech. Eng. 2012, 4, 237379. [CrossRef]

12. Saha, M.K.; Mondal, A.; Hazra, R.; Das, S. An overview on cladding through gas metal arc welding. In Proceedings of the National Welding Seminar, Jamshedpur, India, 22 January 2015; Indian Institute of Welding and Tata Steel: Jamshedpur, India.

13. Khara, B.; Mondal, N.D.; Sarkar, A.; Sarkar, M.; Chakrabarty, B.; Das, S. Weld cladding with austenite stainless steel for imparting corrosion resistance. Ind. Weld. J. 2016, 49, 74-81. [CrossRef]

14. Verma, A.K.; Biswas, B.C.; Roy, P.; De, S.; Soren, S.; Das, S. An investigation on the anti-corrosion characteristics of stainless steel cladding. Ind. Weld. J. 2017, 50, 52-63. [CrossRef]

15. Verma, A.K.; Biswas, B.C.; Roy, P.; De, S.; Saren, S.; Das, S. On The Effectiveness of Duplex Stainless Steel Cladding Deposited by Gas Metal Arc Welding. Ind Weld. J. 2014, 47, 24-32. [CrossRef]

16. Dhib, Z.; Guermazi, N.; Ktari, A.; Gasperini, M.; Haddar, N. Mechanical bonding properties and interfacial morphologies of austenitic stainless steel clad composite. Mater. Sci. Eng. 2017, 696, 374-386. [CrossRef]

17. Dhib, Z.; Guermazi, N.; Gaspérini, M.; Haddar, N. Cladding of low-carbon steel to austenitic stainless steel by hot-roll bonding: Microstructure and mechanical properties properties before and after welding. Mater. Sci. Eng. A. 2016, 656, 130-141. [CrossRef]

18. Li, K.; Li, D.; Liu, D.; Pei, G.; Sun, L. Microstructure evolution and mechanical properties of multiple-layer laser cladding coating of 308L stainless steel. Appl. Surf. Sci. 2015, 340, 143-150. [CrossRef]

19. Yang, K.; Zhang, Z.; Hu, W.; Bao, Y.; Jiang, Y. A new type of submerged-arc flux-cored wire used for hardfacing continuous casting rolls. J. Iron Steel Res. Int. 2011, 18, 74-79. [CrossRef]

20. Vitanov, V.I.; Voutchkov, I.I.; Bedford, G.M. Neurofuzzy approach to process parameter selection for friction surfacing applications. Surf. Coat. Tech. 2001, 140, 256-262. [CrossRef]

21. Li, J.Q.; Shinoda, T. Underwater friction surfacing. Surf. Eng. 2000, 16, 31-35. [CrossRef]

22. Katayama, Y.; Takahashi, M.; Shinoda, T.; Nanbu, K. New Friction Surfacing Application for Stainless Steel Pipe. Weld. World 2009, 53, R272-R280. 
23. Hemmati, I.; Ocelík, V.; De Hosson, J.T.M. The effect of cladding speed on phase constitution and properties of AISI 431stainless steel laser deposited coatings. Surf. Coat. Tech. 2011, 205, 5235-5239. [CrossRef]

24. Wen, P.; Cai, Z.; Feng, Z.; Wang, G. Microstructure and mechanical properties of hot wire laser clad layers for repairing precipitation hardening martensitic stainless steel. Opt. Laser Technol. 2015, 75, 207-213. [CrossRef]

25. Wang, J.B.; Zhou, Y.F.; Xing, X.L.; Liu, S.; Zhao, C.C.; Yang, Y.L.; Yang, Q.X. The effect of nitrogen alloying to the microstructure and mechanical properties of martensitic stainless steel hardfacing. Surf. Coat. Tech. 2016, 294, 115-121. [CrossRef]

26. Oo, H.Z.; Muangjunburee, P. Wear behavior of hardfacing on 3.5\% chromium cast steel by submerged arc welding. Mat. Today Proc. 2018, 5, 9281-9289. [CrossRef]

27. Balakrishnan, M.; Balasubramanian, V.; Madhusudhan Reddy, G. Effect of Hardfacing Consumables on Ballistic Performance of Q\&T Steel Joints. Defence Technol. 2013, 9, 249-258.

28. Venkateswara Rao, N.; Madhusudhan Reddy, G.; Nagarjuna, S. Weld overlay cladding of high strength low alloy steel with austenitic stainless steel-structute and properties. Mater. Des. 2011, 32, 2496-2506. [CrossRef]

29. Mirshekaria, G.R.; Daeeb, S.; FatourehBonabib, S.; Tavakolic, M.R.; Shafyeib, A.; Safaeia, M. Effect of interlayers on the microstructure and wear resistance of Stellite 6 coatings deposited on AISI 420 stainless steel by GTAW technique. Surf. Interface 2017, 9, 79-92. [CrossRef]

30. Rozumek, D.; Kwiatkwoski, G. The influence of heat treatment parameters on the cracks growth under cyclic bending in St-Ti clad obtained by explosive welding. Metals 2019, 9, 338. [CrossRef]

31. Srivastava, S.C.; Murtaza, Q.; Kumar, P. Microwave cladding on metallic surfaces: A review. Mater. Today Proc. 2020, 21, 1533-1536. [CrossRef]

32. Mondal, A.; Saha, M.K.; Hazra, R.; Das, S. Influence of heat input on weld bead geometry using duplex stainless steel wire electrode on low alloy steel specimens. Cogent Eng. 2016, 3, 1143598. [CrossRef]

33. Saha, S.; Mukherjee, M.; Pal, T.K. Microstructure, Texture, and Mechanical Property Analysis of Gas Metal Arc Welded AISI 304 Austenitic Stainless Steel. J. Mater. Eng. Perform. 2015, 24, 1125-1139. [CrossRef]

34. ArslanHafeez, M.; Usman, M.; Arshad, M.A.; AdeelUmer, M. Nanoindentation-Based Micro-Mechanical and Electrochemical Properties of Quench-Hardened. Crystals 2020, 10, 508. [CrossRef]

35. Kou, S. Welding Metallurgy, 2nd ed.; John Wiley \& Sons, Inc.: Hoboken, NJ, USA, 2003.

36. Bjarbo, A.; Hatterstrand, M. Complex carbides growth, dissolution, and coarsening in a modified 12 pct chromium steel-an experimental and theoretical study. Metall. Mater. Trans. A 2001, 32, 19-27. [CrossRef]

37. Clark, D.S.; Varney, W.R. Metallurgy for Engineers; D. Van Nostrand Company: New York, NY, USA, 1965; pp. 206-333.

38. Muddle, B.C.; Nie, J.F. Encyclopedia of Materials: Science and Technology, 2nd ed.; Pergamon-Elsevier: Oxford, UK, 2001. [CrossRef]

39. Ezechidelu, J.C.; Enibe, S.O.; Obikwelu, D.O.; Nnamchi, P.S.; Obayi, C.S. Effect of heat treatment on the microstructure and mechanical properties of a welded AISI 410 martensitic stainless steel. Int. Adv. Res. J. Sci. Eng. Tech. 2016, 3, 6-12. [CrossRef]

40. Rajasekhar, A.; Medhusudhan, G.R.; Mohandas, T.; Murti, V.S.R. Influence of austenitizng temperature on microstructure and mechanical properties of AISI 431 martensitic stainless steel electron beam welds. Mater. Des. 2009, 30, 1612-1624. [CrossRef]

41. Firdus, A.M.H.; Rizam, S.S.; Shamsul, J.B.; Derman, M.N.; Fitri, M.W.M.; Ruhiyudin, M.Z. The effect of heat treatment on the open circuit potential of magnesium sacrificial anode. In Proceedings of the Malaysian Metallurgical Conference, Universiti Kebangsaan Malaysia, Bangi, Selangor, Malaysia, 3-4 December 2008. [CrossRef]

42. Bhaumik, S.; Chowdhury, D.; Batham, A.; Sehgal, U.; Ghosh, C.; Bhattacharya, B.; Datta, S. Analysing the frictional properties of micro dimpled surface created by milling machine under lubricated condition. Tribol. Int. 2020, 146, 106260-106278. [CrossRef]

43. Ramalho, A.; Miranda, J.C. The relationship between wear and dissipated energy in sliding systems. Wear 2006, 260, 361-367. [CrossRef]

(C) 2020 by the authors. Licensee MDPI, Basel, Switzerland. This article is an open access article distributed under the terms and conditions of the Creative Commons Attribution (CC BY) license (http://creativecommons.org/licenses/by/4.0/). 